\title{
Temperature Rising Elution Fractionation of Syndiotactic Polypropylene Prepared by Homogeneous and Supported Metallocene Catalysts
}

\author{
Junting Xu, ${ }^{\dagger}$ Yi Deng, ${ }^{*}$ Linxian Feng, \\ Chunming CUI,* and Wei CHEN* \\ Department of Polymer Science \& Engineering, Zhejiang University, \\ Hangzhou 310027, People's Republic of China \\ * Research Institute of Petroleum Processing, SINOPEC, \\ Beijing 100083, People's Republic of China
}

(Received March 16, 1998)

\begin{abstract}
Two syndiotactic polypropylene (sPP) samples prepared by homogeneous and supported metallocene catalysts respectively were fractionated by preparative temperature rising elution fractionation (TREF). Some fractions were selected for characterization of ${ }^{13} \mathrm{C}$ NMR, DSC, and intrinsic viscosity. Molecular weight and syndiotacticity have different influence on the fractionation of these two samples. In the fractionation of sPP prepared by homogeneous metallocene catalyst (sPP-1), the first eight fractions showed differences mainly in syndiotacticity, but the late fractions had similar syndiotacticity and differed in molecular weight. For the sPP prepared by supported metallocene catalyst (sPP-2), the fractionation is based on syndiotacticity in the whole elution temperature range. The influence of immobilization on the intermolecular heterogeneity and microstructure of polymer was also examined. The fractionation data show that the fractions of sPP-2 have broader syndiotacticity distribution and melting temperature range, indicating that the intermolecular heterogeneity of sPP-2 is more serious than that of sPP-1. This may originate from heterogenization of active site after immobilization of a metallocene catalyst on a carrier. It is also observed that immobilization leads to the decrease of syndiotacticity.
\end{abstract}

KEY WORDS Syndiotactic Polypropylene / Fractionation / Metallocene Catalyst / Characterization /

The metallocene compounds/methylaluminoxane (MAO) catalyst has unique features. ${ }^{1,2}$ To lower the cost of such a catalyst (reflected by reducing the amount of used MAO or partially replacing MAO by common alkylaluminium $^{3,4}$ ) and make use of existing processes and equipment established for polyolefins produced by conventional heterogeneous Ziegler-Natta catalysts, ${ }^{5}$ much work has been carried out to obtain supported metallocene catalysts by immobilizing metallocene catalysts on a carrier. ${ }^{6}$ However, the properties of catalyst and structures of obtained polymers are affected more or less by immobilization. ESR studies showed that additional active sites might be generated in a supported metallocene catalyst. ${ }^{7}$ The change of active site will lead to a polymer microstructure different from that by the corresponding homogeneous catalyst. Kaminsky and Sacchi have prepared isotactic polypropylene by using syndiospecific and aspecific metallocene catalysts supported on $\mathrm{SiO}_{2},{ }^{8,9}$ and Soga obtained atactic polystyrene through $\mathrm{CpTiCl}_{3} / \mathrm{Al}_{2} \mathrm{O}_{3}$ catalyst. $^{10}$

For conventional heterogeneous Ziegler-Natta catalyst, temperature rising elution fractionation (TREF) is useful for obtaining the tacticity distribution of polypropylene and examining the intermolecular homogeneity of polymer. ${ }^{11,12}$ TREF of isotactic polypropylene prepared by homogeneous bis(indenyl) hafnium dichloride catalyst was performed by Mizuno et al. They found that fractionation was conducted according to molecular weight due to the highly homogeneous intermolecular isotacticity distribution. ${ }^{13}$ As far as we know, TREF has been mainly applied to the fractionation of linear low density polyethylene (LLDPE) and isotactic polypropylene (iPP), there appear to be few reports on the application of TREF to syndiotactic polypropylene.

$\dagger$ To whom correspondence should be addressed.
In this paper, two syndiotactic polypropylene samples prepared by homogeneous and supported metallocene catalysts respectively were fractionated by preparative TREF. The mechanism of fractionation and intermolecular heterogeneity of these two samples were compared.

\section{EXPERIMENTAL}

\section{Materials}

Syndiotactic polypropylene (sPP)-1 and sPP-2 were prepared by RIPP SINOPEC in slurry polymerization using homogeneous and supported metallocene catalysts respectively. The homogeneous metallocene catalyst used was $\mathrm{Ph}_{2} \mathrm{C}(\mathrm{Flu})(\mathrm{Cp}) \mathrm{ZrCl}_{2}$. The supported metallocene catalyst was prepared by immobilizing $\mathrm{Ph}_{2} \mathrm{C}(\mathrm{Flu})(\mathrm{Cp})$ $\mathrm{ZrCl}_{2}$ on the surface of pretreated $\mathrm{SiO}_{2}$ according to ref 14. The cocatalyst was $\mathrm{MAO}$ and $\mathrm{Al} / \mathrm{Zr}$ ratio, 2000. Polymerization temperature was $50^{\circ} \mathrm{C}$ and toluene was used as solvent.

\section{Preparative TREF}

Preparative TREF apparatus was used to collect sufficient amounts of polymer fractions. 2 grams of polymer were dissolved in xylene at a concentration of $0.005 \mathrm{~g} \mathrm{ml}^{-1}$ at $130^{\circ} \mathrm{C}$. This solution was deposited on an inert support, sea sand (particle diameter: $0.3-0.6$ $\mathrm{mm}$ ) packed in a steel column. The length and internal diameter of the column are $1.0 \mathrm{~m}$ and $40 \mathrm{~mm}$, respectively. The column was cooled to room temperature at $1.5^{\circ} \mathrm{C}$ $\mathrm{h}^{-1}$. The deposited polymer was heated stepwisely and eluted with xylene. The polymer fractions were recovered by evaporating the xylene solvent and drying in a vacuum oven. Because a small amount of antioxidant 1010 had been added, the total recovery of polymer was around $105 \%$. The fitting of TREF curves was carried out by 
TREF of sPP from Metallocenes

Table I. Fractionation and related data of sPP-1

\begin{tabular}{|c|c|c|c|c|c|c|c|c|}
\hline \multirow{2}{*}{ Fraction } & \multirow{2}{*}{$\frac{\begin{array}{c}\text { Elution } \\
\text { temp }\end{array}}{{ }^{\circ} \mathrm{C}}$} & \multirow{2}{*}{$W_{i} \%$} & \multirow{2}{*}{$\sum W_{i} \%$} & \multirow{2}{*}{$W_{i} \% / \Delta T^{\mathrm{a}}$} & \multirow{2}{*}{$\frac{[r r]}{\%}$} & \multirow{2}{*}{$\frac{\begin{array}{c}\text { Melting } \\
\text { temp }\end{array}}{{ }^{\circ} \mathrm{C}}$} & \multirow{2}{*}{$\frac{[\eta]^{\mathrm{b}}\left(\times 10^{2}\right)}{\mathrm{ml} \mathrm{g}^{-1}}$} & \multirow{2}{*}{$\begin{array}{c}M_{v} \\
\left(\times 10^{-4}\right)\end{array}$} \\
\hline & & & & & & & & \\
\hline sPP-1 & - & - & - & - & 93.0 & - & & \\
\hline Al & 23 & 4.79 & 4.79 & - & & No peak & & \\
\hline $\mathrm{A} 2$ & 40 & 4.28 & 9.07 & 0.252 & & & & \\
\hline A4 & 55 & 0.46 & 10.20 & 0.092 & & & & \\
\hline A5 & 60 & 1.19 & 11.39 & 0.238 & 87.2 & $122.4 / 133.6$ & & \\
\hline A6 & 65 & 2.01 & 13.40 & 0.402 & & $120.8 / 134.5$ & & \\
\hline A 7 & 68 & 3.35 & 16.75 & 1.117 & & $128.7 / 137.5$ & 1.38 & 13.3 \\
\hline A8 & 71 & 5.67 & 22.42 & 1.890 & 93.0 & $131.3 / 139.1$ & 1.40 & 13.5 \\
\hline A9 & 74 & 13.73 & 36.15 & 4.577 & & $131.3 / 137.9$ & & \\
\hline Al0 & 77 & 29.35 & 65.50 & 9.783 & 93.3 & $131.0 / 137.1$ & & \\
\hline A11 & 80 & 14.92 & 80.42 & 4.973 & & $132.1 / 136.8$ & 2.86 & 33.0 \\
\hline A 13 & 87 & 4.17 & 90.46 & 1.043 & & $131.8 / 136.3$ & & \\
\hline A14 & 92 & 4.30 & 94.76 & 0.860 & & & & \\
\hline A 15 & 113 & 5.24 & 100.0 & 0.250 & 93.4 & $131.7 / 136.6$ & 3.72 & 45.9 \\
\hline
\end{tabular}

${ }^{\mathrm{a}} W_{i} \% / \Delta T=W_{i} \% /\left(T_{i}-T_{i-1}\right) . \quad{ }^{\mathrm{b}}$ Intrinsic viscosity.

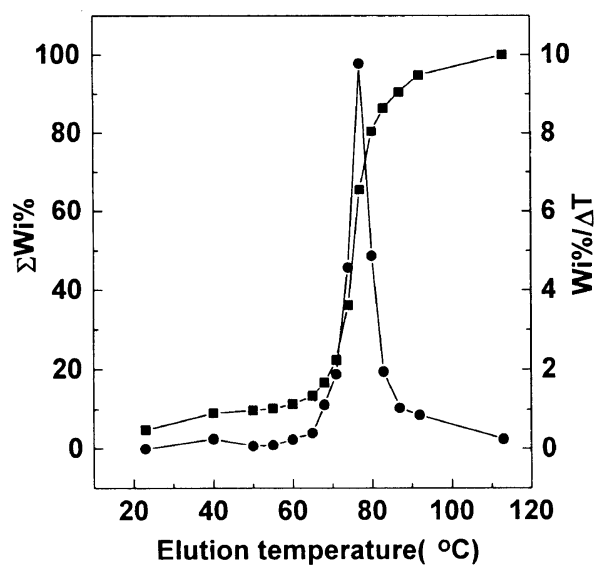

Figure 1. TREF curves of sPP-1 prepared by homogeneous metallocene catalyst. $-\square-\sum W_{i} \% ;-\longrightarrow-W_{i} \% / \Delta T$.

the software, "Microcal Origin (Version 4.0)" for "Windows."

\section{NMR Analysis}

${ }^{13} \mathrm{C}$ NMR spectra were recorded on a Bruker AMX400 spectrometer operated at $100.7 \mathrm{MHz}$ in PFT mode at $370 \mathrm{~K}$. The polymer solutions were prepared by dissolving ca. $50 \mathrm{mg}$ polymer in $0.5 \mathrm{ml} \mathrm{C}_{6} \mathrm{D}_{4} \mathrm{Cl}_{2} 1 \%$ hexamethyldisiloxane (HMDS) was added as internal reference. The pulse angle was $90^{\circ}$, pulse repetition, $10 \mathrm{~s}$, spectral width, $5000 \mathrm{~Hz}$, number of scans, 6000, and data points, $32 \mathrm{~K}$.

\section{Thermal Analysis}

Differential scanning calorimeter (DSC) experiments were performed using a Du Pont Model TA-2100. The weight of sample was $1.5 \mathrm{mg}$. Samples were first heated to $180^{\circ} \mathrm{C}$ and maintained for $5 \mathrm{~min}$ to remove previous heat history. DSC traces were acquired at a heating rate of $10^{\circ} \mathrm{Cmin}^{-1}$.

\section{Viscosity Measurement}

Intrinsic viscosity of the samples was measured with a modified Ubbelohde type viscometer at $135^{\circ} \mathrm{C}$ using decalin as solvent. The concentration of solution was $0.15 \% \mathrm{~g} \mathrm{ml}^{-1}$ and a small amount of antioxidant was added in the solution. ${ }^{15}$ The viscosity-average molecular weight of polymer was calculated using the Mark-Houwink constant $\alpha=0.80$ and $K=11.0 \times 10^{-3} \mathrm{mlg}^{-1}$.

\section{RESULTS AND DISCUSSION}

\section{Fractionation of $S P P-1$}

Figure 1 shows TREF curves of sPP-1 prepared by the homogeneous metallocene catalyst. Fractionation and other related data are summarized in Table I. The $W_{i} \% / \Delta T-T$ curve in Figure 1 approximates the differential of cumulative weight curves. $W_{i} \% / \Delta T-T$ curve in Figure 1 is relatively narrow with only one sharp peak. In contrast, for the iPP prepared by conventional heterogeneous catalysts, $W_{i} \% / \Delta T-T$ curve was broad and multiple peaks were observed. ${ }^{16}$ This suggests that the polymer produced by the homogeneous metallocene catalyst has good intermolecular homogeneity, which may be due to the "single site" of homogeneous metallocene catalyst. This was also evident from the narrower tacticity range of sPP fractions compared with that of iPP. In iPP prepared by heterogeneous ZieglerNatta catalyst, the concentration of $[\mathrm{mm}]$ triad ranged from 0.46 to $1.0,{ }^{16}$ but the concentration of $[r r]$ triad in sPP-1 varied only in the range of about 0.1 .

Examining the variation of melting temperature of fractions with elution temperature, the melting temperatures of initial eight fractions (A1-A8) increased with elution temperature, but the melting temperatures of fractions A8-A14 nearly remained the same. ${ }^{13} \mathrm{C}$ NMR data show that the syndiotacticity of fraction $A 8$ is higher than that of A5, but fractions A8 and A10 have similar syndiotacticity. Fractions A7 and A8 have near molecular weight, while the molecular weight of fraction A11 is twice that of A8. Since the principle of TREF is based on crystallinity of polymer, ${ }^{17}$ both syndiotacticity and molecular weight influence fractionation. Syndiotacticity, melting temperature, and $M_{v}$ imply that in the initial 
Table II. Fractionation and related data of sPP-2

\begin{tabular}{|c|c|c|c|c|c|c|c|c|}
\hline \multirow{2}{*}{ Fraction } & $\begin{array}{l}\text { Elution } \\
\text { temp }\end{array}$ & \multirow{2}{*}{$W_{i} \%$} & \multirow{2}{*}{$\sum W_{i} \%$} & \multirow{2}{*}{$W_{i} \% / \Delta T^{\mathrm{a}}$} & \multirow{2}{*}{$\frac{[r r]}{\%}$} & \multirow{2}{*}{$\frac{\begin{array}{c}\text { Melting } \\
\text { temp }\end{array}}{{ }^{\circ} \mathrm{C}}$} & \multirow{2}{*}{$\frac{[\eta]^{\mathrm{b}}\left(\times 10^{2}\right)}{\mathrm{mlg}^{-1}}$} & \multirow{2}{*}{$\begin{array}{c}M_{v} \\
\left(\times 10^{-4}\right)\end{array}$} \\
\hline & ${ }^{\circ} \mathrm{C}$ & & & & & & & \\
\hline sPP-2 & - & & & & 89.8 & & 3.29 & 37.3 \\
\hline $\mathrm{B} 1$ & 20 & 10.92 & 10.92 & - & - & No peak & & \\
\hline B2 & 55 & 12.70 & 23.62 & 0.363 & 83.4 & $112.4 / 117.8$ & 1.34 & 12.8 \\
\hline B3 & 60 & 2.74 & 26.36 & 0.548 & & & 1.68 & 17.0 \\
\hline B4 & 65 & 9.30 & 35.66 & 1.86 & - & $119.2 / 126.3$ & 2.27 & 24.7 \\
\hline B5 & 68 & 12.48 & 48.14 & 4.16 & 90.7 & $119.6 / 127.3$ & 2.60 & 29.3 \\
\hline B6 & 71 & 17.71 & 65.85 & 5.90 & 91.6 & $124.5 / 130.5$ & 3.12 & 36.8 \\
\hline B7 & 74 & 16.00 & 81.85 & 5.33 & 92.4 & $127.2 / 135.4$ & 3.37 & 40.5 \\
\hline B8 & 77 & 7.99 & 89.84 & 2.66 & 93.3 & $130.8 / 136.7$ & 3.06 & 35.9 \\
\hline B9 & 80 & 3.55 & 93.39 & 1.18 & & & 2.67 & 30.3 \\
\hline B10 & 83 & 2.67 & 96.06 & 0.89 & & & 2.90 & 33.6 \\
\hline B11 & 87 & 2.07 & 98.13 & 0.517 & & & & \\
\hline B12 & 97 & 1.82 & 99.95 & 0.182 & 95.4 & $136.2 / 142.4$ & 2.97 & 34.6 \\
\hline B13 & 110 & 0.053 & 100.00 & 0.004 & & & & \\
\hline
\end{tabular}

${ }^{\mathrm{a}} W_{i} \% / \Delta T=W_{i} \% /\left(T_{i}-T_{i-1}\right) . \quad{ }^{\mathrm{b}}$ Intrinsic viscosity.

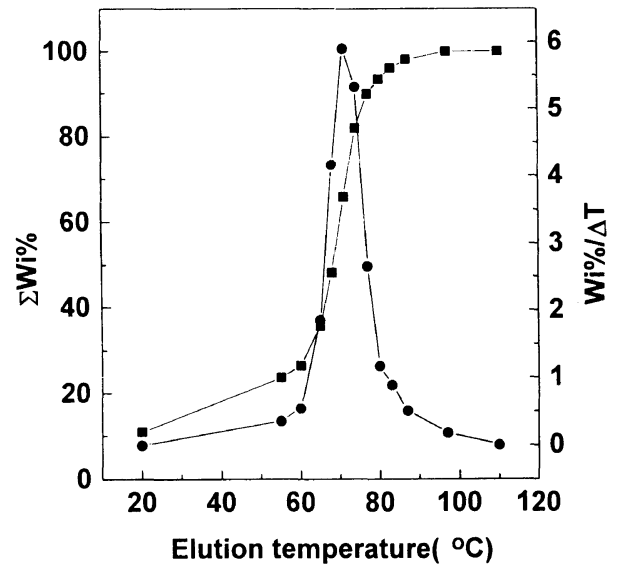

Figure 2. TREF curves of sPP-2 prepared by supported metallocene catalyst. - $-\sum W_{i} \% ;-\bullet-, W_{i} \% / \Delta T$.

eight fractions syndiotacticity has larger effect on fractionation, but fractionation was performed mainly according to molecular weight in the subsequent fractions. It is possible that when there is no substantial difference in syndiotacticity among polymer chains, molecular weight becomes the main factor influencing crystallization. In contrast, the fractionation of iPP prepared by conventional heterogeneous Ziegler-Natta catalysts is based on tacticity due to its broad tacticity distribution. The observed phenomenon in the present work is also different from that in TREF of iPP prepared by Hf-based homogeneous metallocene catalyst. Mizuno found all fractions had similar melting temperatures but different molecular weights and claimed that the fractionation was conducted according to molecular weight throughout the elution temperature range.

\section{Fractionation of $S P P-2$}

Figure 2 shows the TREF curves of sPP-2 prepared by supported metallocene catalyst. Fractionation data and syndiotacticity, molecular weight and melting temperature of some fractions are listed in Table II. ${ }^{13} \mathrm{C}$ NMR data show that the concentration of $[r r]$ triad of fractions increased gradually with elution temperature and fraction B12 had the highest syndiotacticity, though variation was small. The melting temperatures of fractions reveal similar tendency, but the difference in melting temperature is more obvious than that in syndiotacticity. These indicate that in this sample syndiotacticity is the main factor influencing fractionation. The variation of molecular weight of fractions with elution temperature is less regular. In the initial stage it also increases with elution temperature and reaches a maximum for fractions B7, but it varies irregularly in the later fractions. Comparing with the fractionation of sPP-1, the influence of syndiotacticity and molecular weight differs to some extent in the fractionation of SPP-1 and SPP-2. In the case of sPP-1, molecular weight has larger influence, but the fractionation of $\mathrm{sPP}-2$ is mainly based on syndiotacticity. The reason may be the sPP-2 has broader syndiotacticity distribution, considering the broader melting temperature range of its fractions.

It can be seen from Tables I and II that the molecular weights of fractions of SPP- 1 and sPP-2 vary in a broad range. Thus, supported and unsupported catalysts provide broad molecular weight distribution, though much narrower than that of PP prepared with conventional Ziegler-Natta catalyst. ${ }^{16}$

\section{Comparison of $S P P-1$ and $S P P-2$}

The fractions of sPP-2 have broader syndiotacticity range and melting temperature in comparison with sPP-1, indicating that the intermolecular heterogeneity of sPP-2 is more serious than that of sPP-1. This can also be seen from the line widths of $W_{i} \% / \Delta T-T$ curves and maximal values of $W_{i} \% / \Delta T$ in Figures 1 and 2 . Both $W_{i} \% / \Delta T-T$ curves in Figures 1 and 2 can be well fitted by Lorentzian type lines. The half-peak widths of $W_{i} \% / \Delta T-T$ curves for sPP- 1 and sPP-2 were $5.81^{\circ} \mathrm{C}$ and $9.48^{\circ} \mathrm{C}$. The maximal value of $W_{i} \% / \Delta T$ of sPP-2 was smaller than that of sPP-1. Since intermolecular heterogeneity originates from the heterogeneity of active sites, the active sites in the supported metallocene catalyst producing sPP-2 are not so homogeneous as in the homogeneous metallocene catalyst, though the $W_{i} \%$ / $\Delta T-T$ curve of sPP-2 can also be fitted by a single Lorentzian type line. Immobilization of a metallocene catalyst on a carrier may lead to the heterogenization of 
TREF of sPP from Metallocenes

Table III. Pentad distributions of some selected fractions

\begin{tabular}{|c|c|c|c|c|c|c|c|c|c|}
\hline Fraction & $m m m m$ & $m m m r$ & $r m m r$ & $m m r r$ & $m r m m+r m r r$ & $m r m r$ & $r r r r$ & rrrm & mrrm \\
\hline A5 & 0 & 0 & 3.2 & 7.3 & 2.3 & 0 & 80.1 & 7.1 & 0 \\
\hline A 8 & 0 & 0 & 2.0 & 3.5 & 1.5 & 0 & 89.5 & 3.5 & 0 \\
\hline A 15 & 0 & 0 & 1.8 & 3.2 & 1.6 & 0 & 89.9 & 3.5 & 0 \\
\hline B2 & 0 & 1.9 & 3.1 & 6.7 & 5.0 & 0 & 74.9 & 8.5 & 0 \\
\hline B5 & 0 & 0 & 2.3 & 4.5 & 2.4 & 0 & 85.2 & 5.5 & 0 \\
\hline B7 & 0 & 0 & 2.0 & 4.0 & 1.6 & 0 & 87.4 & 5.0 & 0 \\
\hline B8 & 0 & 0 & 2.7 & 3.3 & $0.8^{\prime}$ & 0 & 89.5 & 3.8 & 0 \\
\hline $\mathrm{B} 12$ & 0 & 0 & 1.5 & 3.1 & 0 & 0 & 92.2 & 3.2 & 0 \\
\hline
\end{tabular}

a

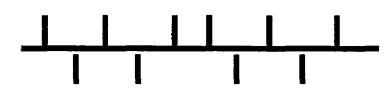

rrrmrrrr

b

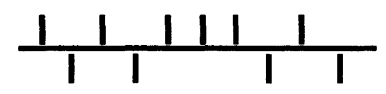

rrrmmrrr

Scheme 1. Two possible structural defects in syndiotactic PP chains.

active site. When $\mathrm{Cp}_{2} \mathrm{TiCl}_{2}$ was supported on $\mathrm{MgCl}_{2}$, Satyanarayana observed multiple ESR signals, whereas single ESR signal appeared in the ESR spectrum of homogeneous $\mathrm{Cp}_{2} \mathrm{TiCl}_{2} / \mathrm{MAO}$ system. ${ }^{7}$ The basic reason for the heterogenization of active sites in supported metallocene catalyst is that the metallocene catalyst can be immobilized in different forms, such as physical adsorption, chemical reaction with different "active spots" on the surface of carrier. ${ }^{18,19}$

Figures 1 and 2 show that the temperatures to which maximal $W_{i} \% / \Delta T$ values correspond are $77^{\circ} \mathrm{C}$ and $71^{\circ} \mathrm{C}$ for sPP-1 and sPP-2 respectively. This is in accordance with the lower whole syndiotacticity of sPP-2. As shown in Tables I and II, total weight percentage of the fractions with syndiotacticity below $93.0 \%$ is $22.56 \%$ for sPP-1 (A1-A7, A15), and 81.85\% for sPP-2 (B1-B7). The overall tacticity of the polymer may change after immobilization. When syndiospecific or aspecific homogeneous catalyst was immobilized on $\mathrm{SiO}_{2}$, isotactic polypropylene was acquired.$^{8,9}$ In the syndiospecific polymerization of styrene, atactic or even isotactic polystyrene was obtained in the presence of the supported $\mathrm{CpTiCl}_{3}$ catalyst. ${ }^{10,20}$ The isospecific catalyst is directly supported, but isotacticity of polypropylene can be improved further. ${ }^{21}$ The immobilization of homogeneous catalyst on the surface of a carrier may enhance the isotacticity of a polymer. For syndiospecific polymerization, isospecific insertion is a propagation error. Therefore immobilization of a metallocene catalyst on a carrier reduces the syndioselectivity of the catalyst, resulting in decrease of syndiotacticity of polymer.

In the ${ }^{13} \mathrm{C}$ NMR spectra of fractions, no peaks originating from head-to-head propylene sequences are detected in any spectra for each fraction and only defects due to stereoirregularity are present along the macromolecular chain. Pentad distribution of some selected fractions is listed in Table III. In the most fractions, only rrr, rrrm, rmmr, mmrr, and rrmr + mmrm pentads are observed, indicating that two structural defects shown in Scheme 1 may coexist in the polymer chain. This agrees with the results obtained by Balbontin et al. ${ }^{22}$ Therefore, immobilization of a metallocene catalyst on a carrier enhances the probability of insertion error, but does not change the polymerization mechanism.

Acknowledgments. This Project 59703002 is supported by National Natural Science Foundation of China.

\section{REFERENCES}

1. S. S. Reddy and S. Sivaram, Prog. Polym. Sci., 20, 309 (1995).

2. J. Huang and G. L. Rempel, Prog. Polym. Sci., 20, 459 (1995).

3. J. C. W. Chien and D. He, J. Polym. Sci., Part A, Polym. Chem., 29, 1603 (1991).

4. K. Soga and M. Kaminaka, Makromol. Chem., 194, 1745 (1993).

5. H. T. Pu and S. N. Habash, "MetCon '95," Houston, TX, 1995.

6. K. Soga, T. Arai, H. Nozawa, and T. Uozumi, Macromol. Symp., 97, 53 (1995) and references therein.

7. G. Satyanarayana and K. Sivaram, Macromolecules, 26, 4712 (1993).

8. W. Kaminsky, Macromol. Symp., 89, 203 (1995).

9. M. C. Sacchi, D. Zucchi, I. Tritto, P. Locatelli, and T. Dall'Occo, Macromol. Chem., Rapid Commun., 16, 581 (1995).

10. K. Soga, R. Koide, and T. Uozumi, Makromol. Chem., Rapid Commun., 14, 511 (1993).

11. M. Kakugo, T. Miyotake, Y. Naito, and K. Mizunuma, Macromolecules, 21, 314 (1989).

12. J. T. Xu, L. X. Feng, S. L. Yang, Y. N. Wu, Y. Q. Yang, and X. M. Kong, Macromol. Chem., Rapid Commun., 17, 645 (1996).

13. A. Mizuno, T. Abiru, M. Motowoka, M. Kioka, and M. Onda, J. Appl. Polym. Sci., Appl. Polym. Symp., 52, 159 (1993).

14. Y. Deng, C. M. Cui, and W. Chen, "Preprints of National Polymer Conference of China," Guangzhou, 1995.

15. Chinese Standard GB 1841-80.

16. J. T. Xu, Y. Q. Yang, L. X. Feng, X. M. Kong, and S. L. Yang, J. Appl. Polym. Sci., 62, 727 (1996).

17. L. Wild, T. R. Ryle, D. C. Knobeloch, and I. R. Peats, J. Polym. Sci., Part B, Polym. Phys., 20, 441 (1982).

18. S. Collins, W. M. Kelly, and D. A. Holden, Macromolecules, 25, 1780 (1992).

19. S. Wang, B. A. Kuntz, S. Nistala, S. Collins, D. Harrison, and I. Coulter, "MetCon '95," Houston, TX, 1995.

20. T. J. Xu, J. Zhao, Z. Q. Fan, and L. X. Feng, Macromol. Chem., Rapid Commun., 18, 875 (1997).

21. W. Kaminsky and F. Renner, Macromol. Chem., Rapid Commun., 14, 239 (1993).

22. G. Balbontin, D. Dainelli, M. Galimbert, and G. Paganett, Makromol. Chem., 193, 693 (1992). 